\title{
Understanding patients' preferences for osteoporosis treatment: the impact of patients' characteristics on subgroups and latent classes
}

\author{
D. Cornelissen ${ }^{1}$ (D) $\cdot$ A. Boonen ${ }^{1,2} \cdot$ S. Bours ${ }^{1,2} \cdot$ S. Evers ${ }^{1,3} \cdot$ C. Dirksen $^{4} \cdot$ M. Hiligsmann ${ }^{1}$
}

Received: 6 April 2019 / Accepted: 30 August 2019/Published online: 12 October 2019

(C) The Author(s) 2019

\begin{abstract}
Summary This study revealed patterns in osteoporosis patients' treatment preferences, which cannot be related to sociodemographic or clinical characteristics, implicating unknown underlying reasons. Therefore, to improve quality of care and treatment, patients should have an active role in treatment choice, irrespective of their characteristics.

Introduction Patient centeredness is important to improve the quality of care. Accounting for patient preferences is a key element of patient centeredness, and understanding preferences are important for successful and adherent treatment. This study was designed to identify different preferences profiles and to investigate how patient characteristics influence treatment preferences of patients for anti-osteoporosis drugs.

Methods Data from a discrete choice experiment among 188 osteoporotic patients were used. The hypothetical treatment options were characterized by three attributes: treatment efficacy, side effects, and mode/frequency of administration. A mixed logit model was used to measure heterogeneity across the sample. Subgroup analyses were conducted to identify potential effect of patient characteristics. Latent class modeling (LCM) was applied. Associations between patients' characteristics and the identified latent classes were explored with chi-square.

Results All treatment options were important for patients' decision regarding osteoporotic treatment. Significant heterogeneity was observed for most attributes. Subgroup analyses revealed that patients with a previous fracture valued efficacy most, and patients with a fear of needles or aged $>65$ years preferred oral tablets. Elderly patients disliked intravenous medication. Three latent classes were identified, in which 6-month subcutaneous injection was preferred in two classes (86\%), while oral tablets were preferred in the third class (14\%). No statistically significant associations between the profiles regarding socio-demographic or clinical characteristics could be found.

Conclusions This study revealed patterns in patients' preferences for osteoporosis treatment, which cannot be related to specific sociodemographic or clinical characteristics. Therefore, patients should be involved in clinical decision-making to reveal their preferences.
\end{abstract}

Keywords Comparison $\cdot$ Discrete choice experiment $\cdot$ Drug treatment $\cdot$ Osteoporosis $\cdot$ Patients $\cdot$ Preferences

D. Cornelissen

d.cornelissen@maastrichtuniversity.nl

1 Department of Health Services Research, CAPHRI Care and Public Health Research Institute, Maastricht University, P.O. Box 616, 6200 MD Maastricht, The Netherlands

2 Department of Internal Medicine, Rheumatology, Maastricht University Medical Centre and CAPHRI, Maastricht University, Maastricht, The Netherlands

3 Centre for economic evaluation, Trimbos Institute, Netherlands Institute of Mental Health and Addiction, Utrecht, The Netherlands

4 Department of Clinical Epidemiology and Medical Technology Assessment, CAPHRI, Maastricht University, Maastricht, The Netherlands

\section{Introduction}

Patients' preferences regarding osteoporosis treatment are important when aiming for successful treatment. It is well known that adherence to anti-osteoporosis medications is suboptimal, resulting in decreased treatment benefits and increased costs $[1,2]$. Patients, whose individual beliefs, values, and preferences regarding anti-osteoporosis medications have been taken into account during the decision-making process, experience better quality of care and may reveal better adherence [2]. Therefore, in order to optimize the treatment benefits, patients' preferences have to be investigated and to be incorporated within clinical guidelines and policy decisions [3, 4]. 
In a recent study, patients' preferences for osteoporosis treatment were studied in seven European countries, by means of a discrete choice experiment (DCE) [5]. This study revealed that different treatment aspects, i.e., efficacy, safety, and mode of administration, were important for patients with osteoporosis within the seven countries. There was however a large heterogeneity within as well as between countries. The impact of individual patient characteristics on preferences were not assessed in this study, although it is known that background characteristics such as age, gender, or clinical factors (e.g., prior fracture) could potentially influence patients' preferences [6]. Further research investigating presence of differences between potentially relevant subgroups could therefore be of importance, as emphasized by Laba [7]. On a same line, latent class models are nowadays increasingly used to model preference heterogeneity in health [8]. In latent class models, respondents are classified into different subgroups based on their response on choices or alternatives and such models could thus allow the identification of different profiles of respondents.

Understanding preference heterogeneity and the potential impact of covariates on patients' preferences could provide relevant information for clinicians to optimize osteoporosis care. The aims of this study were therefore to identify single patient characteristics that influence preferences for anti-osteoporotic drugs and to explore existence of profiles of patient profiles of preferences for osteoporotic drugs and to investigate how patient characteristics influence treatment profiles.

\section{Methods}

Data from the Dutch patients who participated in the European DCE $(n=188)$ were used [5]. Patients with, or at risk for, osteoporosis to whom medication or lifestyle changes were proposed were recruited at the osteoporosis or rheumatology outpatient clinics. In a paper-based questionnaire, patients were asked to make a series of hypothetical choices between two unlabeled drug alternatives that varied along several attributes of interest (and a no treatment option). The three attributes in the European DCE were (I) efficacy of the treatment, (II) side effects, and (III) mode and frequency, fixed in a prespecified number of combinations, of administration [9, 10]. Additional information regarding the selection of attributes, experimental design, recruitment, questionnaires, and data analysis can be found in previous publications [5, 11]. The list of attributes and levels as well as an example of a choice task can be found in Fig. 1.

The paper-based questionnaires contained 16 choice tasks. In addition, several questions regarding patients' characteristics were included. Socio-demographic (age, gender, educational level, household size, household net monthly income), medical (self-reported osteoporosis, using anti-osteoporosis medication, ulcer, and/or gastro-intestinal (GI) problems), and other characteristics (body mass index (BMI), patient's perceived wellbeing (measured with a VAS (visual analog scale)), problems taking medication orally, afraid of needles) were collected.

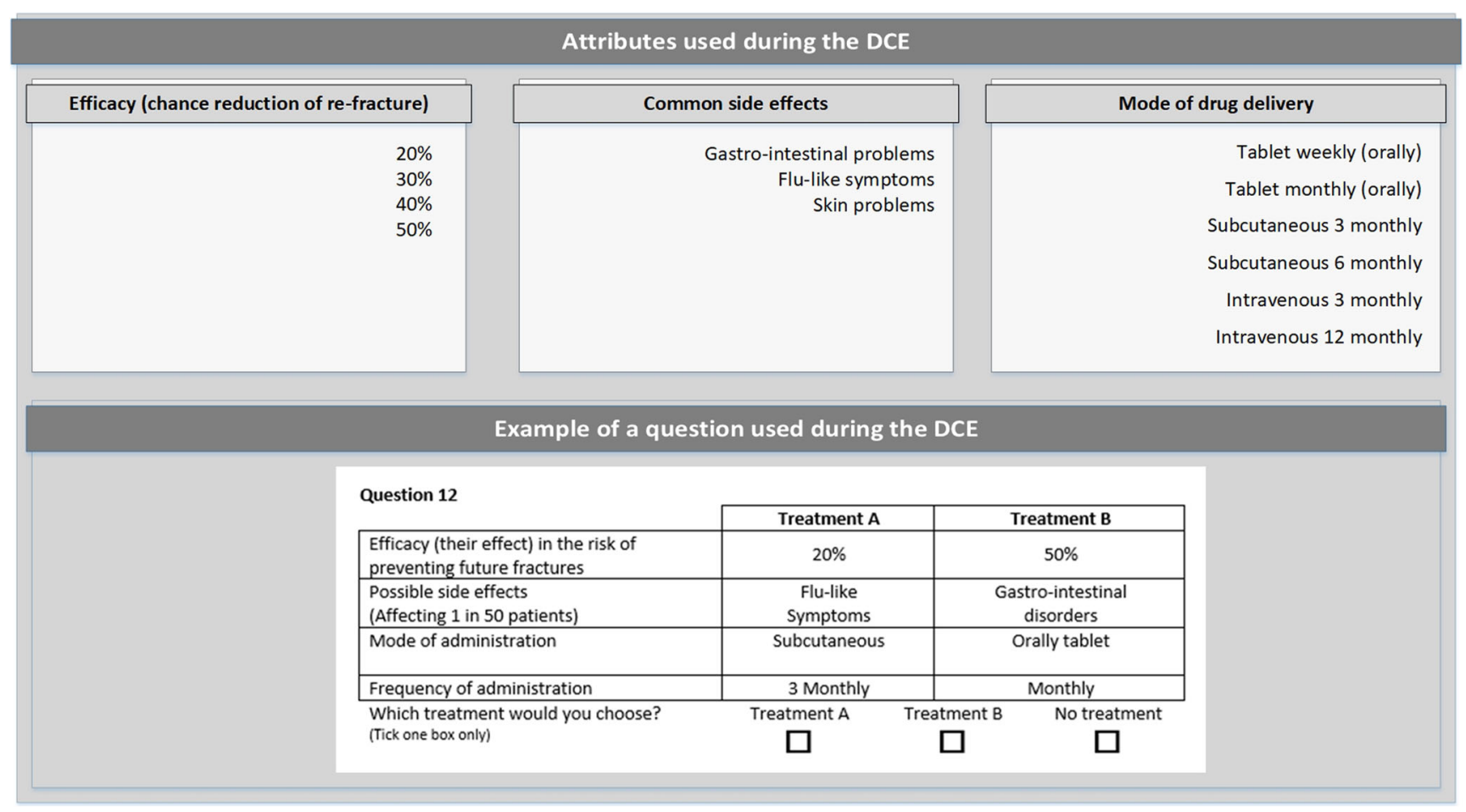

Fig. 1 Attributes, levels, and an example of a choice task 


\section{Statistical analysis}

Various statistical methods were used to explore heterogeneity in patient's preferences, as described below.

First, a mixed logit model (MXL) was used which allows to measure heterogeneity within the entire sample [12]. This model allows model parameters (preferences) to vary in the population. The variation is quantified by a random parameter characterized by a mean $(\beta)$ and standard deviation of the error term $(\eta)$ to capture the parameter's distribution. If the standard deviation is significantly different from zero, this is interpreted as evidence of significant preference heterogeneity for the attribute/level in the sample. The random parameter for the attribute "efficacy" was drawn from a log-normal distribution, this allows us to constrain the parameter estimate to be positive [12]. All other random parameters were drawn from a normal distribution. The estimation was conducted using 2000 Halton draws. The mixed logit model identifies attributes for which there is significant preference heterogeneity, but it does not explain why this heterogeneity exists.

The attribute "efficacy" was analyzed as a continuous variable. All other attributes were included as effects-coded categorical variables. Instead of using dummy coding, we used effect coding, a technique in which the effects are not directly correlated to the intercept and the effect of the reference value is the negative sum of all other characteristics. For the attribute side effects, gastro-intestinal problems were used as the reference value while weekly tablets were used as reference for mode of administration [13-15]. A positive regression coefficient (beta) suggests that patients prefer an increase of a level within an attribute, whereas a negative coefficient suggests that patients prefer a decrease of a level within an attribute. To facilitate interpretation of the coefficient, the importance of each attribute was defined as the difference between the highest and lowest coefficients of each attribute divided by the total sum of these differences [16].

Second, to understand the potential sources of preference heterogeneity, subgroup analyses were conducted including the following covariates that were considered during the design phase of the study as potentially relevant for future subgroup analyses: gender (male vs. female), age ( $<65$ years of age vs. $\geq 65$ years of age), having suffered from a prior fracture (suffered a fracture vs. did not suffered from a fracture), and fear of needles. Joint models were estimated using interaction terms to investigate significant difference among people with different characteristics.

Third, a latent class model (LCM) was used to identify preference profiles of patients. A LCM relates a set of observed data (the preferences as reported by the patients) to a set of unobserved (latent) data, and resulting in classification of patients in latent in classes, based on their responses on during the DCE. As a result of using unobserved data, the chance of a Type I error (unjustified rejecting a null hypothesis) will be reduced [17]. In addition, a LCM has the advantage that it allows to classify patients into classes, which represent a subpopulation in the study population, rather than compare patients on an individual level [18]. The LCM can also be used to explore if covariates (such as gender or having a previous fracture) influence the probability to belong to a particular class. Class membership is latent in that each respondent belongs to each class up to a modeled probability [19]. Therefore, a LCM is a suitable tool to gain insight into the existence and number of classes in the respondent sample, based on their treatment preferences instead of, e.g., clinical or socio-demographic characteristics. To determine the number of classes, the model with the best fit explained based on Akaike's Information Criterion (AIC) was selected [20]. Patients were allocated to the latent class in which the patient had the highest fit.

Finally, we investigated if the latent classes differed according to all the patients' characteristics described above. Since the parameters were categorical, chi-squared tests were used to test whether parameters significantly differed across latent classes. The data were dichotomized or stratified when possible. For the chi-square analysis, a significance level of $<0.05$ was regarded as statistical significant. The MXL and LCM were build and analyzed with the software package of Nlogit V.5.28. The chi-square tests were analyzed with IBM SPSS $24^{\mathrm{TM}}$

\section{Results}

\section{Patient characteristics}

Data of 188 patients were used. Patients were mostly female (78\%), with an average age of 66 years (SD 11, range 23 88 years). Seventy percent of the patients had osteoporosis, and $49 \%$ used currently anti-osteoporosis medication. Thirtyeight percent of the patients suffered from a previous fracture and $79 \%$ suffered from GI problems. The educational level of $60 \%$ of the patients was middle vocational education or higher. Most patients had a household with one partner (67\%) and an average net income between 1500 and 2500 Euro monthly (42\%). Almost half of the patients (49\%) were overweight or obese. More than 1 in 4 patients rated their perceived wellbeing relatively poor, with a VAS score of $<$ 50 . Finally, $21 \%$ of the patients reported having fear of needles and $93 \%$ of the patients reported some problems taking medication orally. A summary of all patients' characteristics can be found in Table 1 .

\section{Mixed logit model}

All attributes (efficacy, side effects, and mode of administration) were statistically significant. Efficacy was the most 
Table 1 Patient characteristics of the total sample $(n=188)$

Demographic characteristics

Age

(Mean, SD)

Gender

Female

Male

Missing

Educational level

Primary school

High school

Occupational education

College level

Missing

Household size (including patient)

1

2

$>2$

Household net monthly income

$<1500$

$1500-2500$

$>2500$

Missing

Self-reported osteoporosis

Yes

No

Suffered from a previous fracture

Yes

No

Missing

Using anti-osteoporosis medication Yes

No

Missing

Ulcer or GE problems

Yes

No

Missing

Body mass index (BMI)

$<20$ (underweight)

20-25 (healthy weight)

$>25$ (overweight and obese)

Missing

Perceived wellbeing (VAS)

$<0.50$

$0.51-0.75$

$>0.75$

Missing

Problems taking medication orally

Yes

No

Missing

Afraid of needles

Yes

No

Missing
$66(10.85)$

$121(78 \%)$

$34(22 \%)$

33

$15(9 \%)$

$51(31 \%)$

$69(42 \%)$

$30(18 \%)$

23

$36(22 \%)$

$111(66 \%)$

$20(12 \%)$

21

$37(25 \%)$

$64(42 \%)$

$50(33 \%)$

37

$116(70 \%)$

$50(30 \%)$

22

$63(38 \%)$

$101(62 \%)$

24

$81(49 \%)$

$84(51 \%)$

23

$133(79 \%)$

$35(21 \%)$

20

$10(6 \%)$

$73(45 \%)$

79 (49\%)

26

$25(15 \%)$

$104(61 \%)$

$41(24 \%)$

17

$155(93 \%)$

$11(7 \%)$

22

$35(21 \%)$

$134(79 \%)$

19 important attribute (relative importance 39\%), followed by mode of administration (relative importance $31 \%$ ) and side effects (relative importance 30\%). Significant heterogeneity was observed for most of the attribute parameters suggesting variations in the levels of attributes. In general, patients favored skin problems and flu-like symptoms over GI problems. In addition, the treatment options with the lowest frequency were less favored than the same treatment options with a lower dosage frequency. Patients preferred subcutaneous treatment every 6 months and monthly oral tablets more compared to the other modes of administration. The results of the mixed logit model can be found in Table 2. Given the significant standard deviation for most coefficients, variations in preferences between patients were observed for all attributes,

\section{Subgroup analyses}

Subgroup analyses resulted in differences between the relative importance of the attributes. Between the subgroups, side effects were the attribute of which the relative importance had 
Table 2 Mixed logit model and latent class analysis

\begin{tabular}{|c|c|c|c|c|}
\hline & MXL & LCM & & \\
\hline Pseudo $R$ squared & 0.38 & 0.43 & & \\
\hline \multirow[t]{2}{*}{ Log likelihood } & -1883.78 & -1753.05 & & \\
\hline & All patients $(n=187)$ & Latent group 1: $(n=122)$ & Latent group 2: $(n=39)$ & Latent group 3: $(n=26)$ \\
\hline Constant & $\begin{array}{l}-1.61 * \\
(95 \% \mathrm{CI}-1.76 /-1.45)\end{array}$ & $\begin{array}{l}0.77 * \\
(95 \% \text { CI } 0.34 / 1.19)\end{array}$ & $\begin{array}{l}-0.97 * \\
(95 \% \mathrm{CI}-1.70 /-0.24)\end{array}$ & $\begin{array}{l}-1.61 * \\
(95 \% \mathrm{CI}-2.42 /-0.80)\end{array}$ \\
\hline Efficacy & $\begin{array}{l}2.34 * \\
(95 \% \text { CI } 2.04 / 2.70)\end{array}$ & $\begin{array}{l}1.07 * \\
(95 \% \text { CI } 1.06 / 1.07)\end{array}$ & $\begin{array}{l}1.05^{*} \\
(95 \% \text { CI } 1.03 / 1.07)\end{array}$ & $\begin{array}{l}1.01 \\
(95 \% \text { CI } 0.99 / 1.03)\end{array}$ \\
\hline $\begin{array}{l}\text { Side effects; } \\
\text { Gastro-intestinal problems }{ }^{1}\end{array}$ & -1.11 & -0.20 & -2.49 & -0.00 \\
\hline $\begin{array}{l}\text { Side effects; } \\
\text { Flu-like symptoms }\end{array}$ & $\begin{array}{l}0.68 * \\
(95 \% \text { CI } 0.46 / 0.90)\end{array}$ & $\begin{array}{l}0.16^{*} \\
(95 \% \text { CI } 0.06 / 0.27)\end{array}$ & $\begin{array}{l}1.23 * \\
(95 \% \text { CI } 0.90 / 1.57)\end{array}$ & $\begin{array}{l}0.26 \\
(95 \% \mathrm{CI}-0.10 / 0.63)\end{array}$ \\
\hline Side effects; on the skin & $\begin{array}{l}0.43 * \\
(95 \% \text { CI } 0.24 / 0.63)\end{array}$ & $\begin{array}{l}0.04 \\
(95 \% \mathrm{CI}-0.06 / 0.14)\end{array}$ & $\begin{array}{l}1.26 * \\
(95 \% \text { CI } 0.92 / 1.60)\end{array}$ & $\begin{array}{l}-0.26 \\
(95 \% \mathrm{CI}-0.64 / 0.11)\end{array}$ \\
\hline Tablet weekly $^{1}$ & -0.26 & -0.31 & -0.38 & 0.77 \\
\hline Tablet monthly & $\begin{array}{l}0.66 * \\
(95 \% \text { CI } 0.45 / 0.86\end{array}$ & $\begin{array}{l}0.32 * \\
(95 \% \text { CI } 0.16 / 0.49)\end{array}$ & $\begin{array}{l}-0.20 \\
(95 \% \mathrm{CI}-0.65 / 0.24)\end{array}$ & $\begin{array}{l}1.06 * \\
(95 \% \text { CI } 0.63 / 1.49)\end{array}$ \\
\hline Subcutaneous 3 monthly & $\begin{array}{l}-0.04 \\
(95 \% \mathrm{CI}-0.28 / 0.19\end{array}$ & $\begin{array}{l}-0.10 \\
(95 \% \mathrm{CI}-0.25 / 0.04)\end{array}$ & $\begin{array}{l}0.33 \\
(95 \% \mathrm{CI}-0.09 / 0.75)\end{array}$ & $\begin{array}{l}-0.81 * \\
(95 \% \mathrm{CI}-1.52 /-0.11)\end{array}$ \\
\hline Subcutaneous 6 monthly & $\begin{array}{l}0.56^{*} \\
(95 \% \text { CI } 0.20 / 0.93)\end{array}$ & $\begin{array}{l}0.37 * \\
(95 \% \text { CI } 0.20 / 0.55)\end{array}$ & $\begin{array}{l}0.55 * \\
(95 \% \text { CI } 0.07 / 1.02)\end{array}$ & $\begin{array}{l}-0.91 * \\
(95 \% \mathrm{CI}-1.56 /-0.27)\end{array}$ \\
\hline Intravenous 3 monthly & $\begin{array}{l}-1.18 * \\
(95 \% \mathrm{CI}-1.52 /-0.84)\end{array}$ & $\begin{array}{l}-0.51 * \\
(95 \% \mathrm{CI}-0.74 /-0.28)\end{array}$ & $\begin{array}{l}-0.50 * \\
(95 \% \mathrm{CI}-0.93 /-0.06)\end{array}$ & $\begin{array}{l}-0.47 \\
(95 \% \mathrm{CI}-1.12 / 0.18)\end{array}$ \\
\hline Intravenous 12 monthly & $\begin{array}{l}0.26 \\
(95 \% \mathrm{CI}-0.07 / 0.60)\end{array}$ & $\begin{array}{l}0.23 * \\
(95 \% \text { CI } 0.02 / 0.44)\end{array}$ & $\begin{array}{l}0.20 \\
(95 \% \mathrm{CI}-0.16 / 0.55)\end{array}$ & $\begin{array}{l}0.37 \\
(95 \% \text { CI } 0.21 / 0.94)\end{array}$ \\
\hline
\end{tabular}

${ }^{1}$ Reference value

* Significance relevant outcome $(p \leq 0.05)$

CI confidence interval

the smallest range (range 28-68\%). Efficacy (range 28-68\%) mode of administration (range 8-37\%) showed wider ranges. Within the subgroups, only few significant differences were observed within the three subgroup analyses. First, patients who have suffered from a previous fracture valued efficacy more than patients who did not suffer from a previous fracture. Second, older patients and patients with fear of needles disfavor the treatment option with intravenous medication and they favor monthly oral tablet more. In addition, for these patients, mode of administration was the most important attribute and side effects the least important attribute. For all other attributes, no other significant differences were observed. The summarized results are presented in Table 3. Detailed results, including coefficient per subgroup and the significance of the differences within the subgroups, are presented in Appendix Tables 5, 6, 7, 8, and 9 .

\section{Latent class model}

Three latent classes of patients were identified, one patient could not be classified and was therefore excluded which resulted in a sample of 187 patients. About $65 \%$ of patients were allocated in latent class 1,21\% in latent class 2, and $14 \%$ in latent class 3. Efficacy was deemed equally important for latent class 1 and 2, and did not reach statistical significance in latent class 3. GI problems were the most disliked side effect in latent classes 1 and 2, and skin problems the most disliked side effect in the latent class 3 .

In class 1, subcutaneous injections every 6 months and monthly tablets and annual intravenous administration of the medication were the most preferred mode of administration. For the latent class 2 , subcutaneous injections every 6 months were the preferred mode of administration. In class 3 , monthly and weekly oral tablets were preferred while the subcutaneous injections every 6 months were a mode of administration patients disliked. Finally, for each mode of administration, the option with the lowest dosage frequency was favored in all latent classes.

\section{Chi-square analysis}

When assessing the differences of the individual patient characteristics between the latent classes, no statistical significant differences were found. In Table 4, the patient characteristics for the whole population and each individual latent class are presented. 
Table 3 Subgroup analysis

\begin{tabular}{lllll}
\hline Subgroup analysis & Gender & Age & Previous fracture & Fear of needles \\
\hline Parameter & Female & $>65$ years & Yes & Yes \\
Constant & & & + & \\
Efficacy & & $*$ & $*$ \\
Side effects & $*$ & $*$ & $*$ & \\
Gastro-intestinal problems & & & & \\
Flu-like symptoms & & & & \\
Skin problems & & $*$ & & \\
Mode of administration & $*$ & + & & \\
Tablet weekly & & & & \\
Tablet monthly & & & & \\
Subcutaneous 3 monthly & & - & & \\
Subcutaneous 6 monthly & & & & \\
Intravenous 3 monthly & & & & \\
Intravenous 12 monthly & & & & \\
\hline
\end{tabular}

+ A statistical significant $(p \leq 0.05)$ preference for the option

- A statistical significant $(p \leq 0.05)$ dislike for the option

*Reference value, therefore unable to assess the statistical significant difference

\section{Discussion}

In this study, the influences of patient characteristics and heterogeneity among osteoporosis patients on preferences for osteoporosis treatment were investigated. The population consisted of a heterogeneous group of patients, who considered the three attributes (1, efficacy; 2, mode (including frequency) of administration; and 3, side effects) of importance. For the attribute mode of administration, there was little difference between the subgroups. The wide range of relative importance for the attributes efficacy and side effects suggests a trade-off between efficacy and mode of administration within the subgroups. In addition, there were only limited variations in preferences between subgroups (age, gender, and having suffered from a previous fracture). Patients aged $\geq 65$ preferred oral medication over intravenous medication. Patients whom have suffered from a previous fracture valued efficacy of medication more than patients without a previous fracture. There was no difference in preference between genders. In addition, three latent classes, each with its own pattern in treatment preferences, based on the patient preferences, were identified. Patients were not evenly distributed over these three classes, about two-third of patients were allocated in one class.

In two out of three latent classes, GI problems were the most disliked side effect, which is comparable with the results of Hiligsmann et al. [5, 11], and subcutaneous injections every 6 months were the preferred mode of administration. In the third latent class, skin problems were the most disliked side effect and oral tablets were the preferred mode of administration. To our knowledge, few studies have investigated the impact of covariates on preferences of osteoporosis medication, none of them comparable to our study. Therefore, we compare our outcomes with studies in which the preferences of osteoporosis patients were studied. The findings concerning other patient preferences were similar to the findings of Weiss et al., who reported that patients value effectiveness over mode and frequency of administration of medication [21]. Our findings are however in contrast with Silverman et al. who described that age, gender, educational level, and income were associated with the preferred mode of osteoporosis treatment administration $[6,22]$. In this study, other parameters, such as ethnicity and age, were included. When concerning frequency of administration, patients in latent classes 1 and 2 disliked weekly tablets which were also observed in the preferred study [23]. This observation is important because currently weekly tablets are the preferred choice of treatment according to the current osteoporosis guidelines, but thus not the preferred treatment option by patients [24].

While it seems that the identification of the three latent classes is of limited clinical value, since they are not directly matched with the individual patient, it does have an important implication. As different patterns in treatment preferences were observed which cannot be related to socio-demographic or clinical patient characteristics, it would thus be important in the clinical decision-making to investigate the preference of each individual patient and involve the patient in the choice of treatment option which they feel suits their needs.

Involvement of patients in clinical decision-making could reduce the burden of non-adherence. However, health care professionals are not always able to provide patients with the proper information $[25,26]$. Therefore, to assist physicians and patients with the choice regarding osteoporosis treatment and to enhance therapy adherence by involving patients in the decision-making process, a decision aid (DA) in which patients with osteoporosis 
Table 4 Patient characteristics in the different latent classes

\begin{tabular}{|c|c|c|c|c|c|}
\hline \multicolumn{5}{|l|}{ Group } & \multirow{2}{*}{$\begin{array}{l}\text { Chi-square test } \\
p \text { value }\end{array}$} \\
\hline Characteristics & $\begin{array}{l}\text { All patients } \\
(N=187)\end{array}$ & $\begin{array}{l}\text { Latent group } 1 \\
(N=122)\end{array}$ & $\begin{array}{l}\text { Latent group } 2 \\
(N=39)\end{array}$ & $\begin{array}{l}\text { Latent group } 3 \\
(N=26)\end{array}$ & \\
\hline Age & & & & & $p=0.49$ \\
\hline$<65$ & $82(48 \%)$ & $55(51 \%)$ & $18(47 \%)$ & $9(38 \%)$ & \\
\hline$>65$ & $88(52 \%)$ & $53(49 \%)$ & $20(53 \%)$ & $15(63 \%)$ & \\
\hline Gender & & & & & $p=0.96$ \\
\hline Male & $34(22 \%)$ & $23(23 \%)$ & $7(21 \%)$ & $4(25 \%)$ & \\
\hline Female & $120(78 \%)$ & $78(77 \%)$ & $26(79 \%)$ & $16(75 \%)$ & \\
\hline Educational level & & & & & $p=0.57$ \\
\hline Primary school & $15(9 \%)$ & $11(11 \%)$ & $3(8 \%)$ & $1(4 \%)$ & \\
\hline High school & $51(31 \%)$ & $35(34 \%)$ & $9(24 \%)$ & $7(29 \%)$ & \\
\hline Vocational education & $69(42 \%)$ & $40(39 \%)$ & $18(46 \%)$ & $10(42 \%)$ & \\
\hline College & $30(18 \%)$ & $17(17 \%)$ & $7(19 \%)$ & $6(25 \%)$ & \\
\hline Household size & & & & & $p=0.93$ \\
\hline 1 & $36(22 \%)$ & $22(21 \%)$ & $10(26 \%)$ & $4(16 \%)$ & \\
\hline 2 & $110(67 \%)$ & $67(65 \%)$ & $25(66 \%)$ & $18(72 \%)$ & \\
\hline$>2$ & $20(12 \%)$ & $14(14 \%)$ & $3(8 \%)$ & $3(12 \%)$ & \\
\hline Income & & & & & $p=0.59$ \\
\hline$<1500$ & $37(25 \%)$ & $19(20 \%)$ & $11(31 \%)$ & $7(32 \%)$ & \\
\hline $1500-2500$ & $64(42 \%)$ & $40(47 \%)$ & $12(34 \%)$ & $8(36 \%)$ & \\
\hline$>2500$ & $49(33 \%)$ & $30(33 \%)$ & $12(34 \%)$ & $7(32 \%)$ & \\
\hline BMI & & & & & $p=0.48$ \\
\hline$<20$ (underweight) & $3(2 \%)$ & $3(3 \%)$ & $0(0 \%)$ & 0 & \\
\hline 20-25 (healthy weight) & $80(49 \%)$ & $50(49 \%)$ & $21(58 \%)$ & $9(39 \%)$ & \\
\hline$<25$ (overweight and obese) & $78(49 \%)$ & $49(38 \%)$ & $15(42 \%)$ & $14(61 \%)$ & \\
\hline Osteoporosis & & & & & $p=0.63$ \\
\hline Yes & $116(70 \%)$ & $73(71 \%)$ & $28(74 \%)$ & $15(63 \%)$ & \\
\hline No & $49(30 \%)$ & $30(29 \%)$ & $10(26 \%)$ & $9(38 \%)$ & \\
\hline Anti-osteoporosis medication & & & & & $p=0.37$ \\
\hline Yes & $81(49 \%)$ & $47(45 \%)$ & $21(57 \%)$ & $13(57 \%)$ & \\
\hline No & $83(51 \%)$ & $57(55 \%)$ & $16(43 \%)$ & $10(44 \%)$ & \\
\hline Prior fracture & & & & & $p=0.36$ \\
\hline Yes & $63(38 \%)$ & $42(40 \%)$ & $11(30 \%)$ & $10(48 \%)$ & \\
\hline No & $100(62 \%)$ & $63(60 \%)$ & $26(70 \%)$ & $11(52 \%)$ & \\
\hline Ulcer or GE problems? & & & & & $p=0.56$ \\
\hline Yes & $132(79 \%)$ & $85(80 \%)$ & $27(73 \%)$ & $20(83 \%)$ & \\
\hline No & $35(21 \%)$ & $21(20 \%)$ & $10(27 \%)$ & $4(17 \%)$ & \\
\hline Afraid of needles & & & & & $p=0.33$ \\
\hline Yes & $35(21 \%)$ & $26(24 \%)$ & $5(14 \%)$ & $4(17 \%)$ & \\
\hline No & $133(79 \%)$ & $81(76 \%)$ & $32(87 \%)$ & $20(83 \%)$ & \\
\hline Problems taking medication orally & & & & & $p=0.55$ \\
\hline Yes & $154(93 \%)$ & $95(92 \%)$ & $36(97 \%)$ & $23(92 \%)$ & \\
\hline No & $11(7 \%)$ & $8(8 \%)$ & $1(3 \%)$ & $2(8 \%)$ & \\
\hline Perceived wellbeing (VAS) & & & & & $p=0.33$ \\
\hline$<0.50$ & $46(27 \%)$ & $32(30 \%)$ & $8(21 \%)$ & $5(20 \%)$ & \\
\hline $0.51-0.75$ & $83(49 \%)$ & $52(49 \%)$ & $21(55 \%)$ & $10(40 \%)$ & \\
\hline$>0.75$ & $41(24 \%)$ & $22(21 \%)$ & $9(24 \%)$ & $10(40 \%)$ & \\
\hline
\end{tabular}


can choose their preferred treatment could be a valuable addition to current treatment [27-32]. In a DA, patients are often presented with the full range of treatment possibilities and information regarding the administration of the drug, effectiveness, and side effects [33, 34]. Since preferences can differ over time, once a patient has made decision patients should be followed up regularly to check or the treatment is still in accordance with the patients' preferences [35].

This study has some potential limitations. First, there were missing data, mainly concerning patient characteristics, especially for the socio-demographic parameters net household income. Since the data-collection was anonymously conducted in 2012, we were unable to clarify inconsistent answers or supplement missing data. Second, the low sample size for some of the characteristics could potentially be a limitation. Third, the questionnaires on patient characteristics and medical information were anonymously, self-completed by the patients and could not be cross-checked in, for example, medical records. Fourth, not all relevant socio-demographic and clinical characteristics were collected, such as ethnicity. The FRAX (Fracture Risk Assessment Tool) score was also not incorporated in the analysis due to the absence of data. Knowledge of the risk of a new fracture could potentially influence patient preferences [36].
In conclusion, this study revealed patterns in patients' preferences for osteoporosis treatment which cannot be related to specific socio-demographic or clinical characteristics. This implicates underlying causes for the preferences which were not observed. This unique finding could be a potential entry point for additional patient preferences research, revealing latent causes influencing non-adherence.

While acknowledging the complexity of this matter and the need for further investigation, the importance of improving therapy adherence urges that patients should be offered a more active role in the choice of treatment, tailored to their preferences, fears, and believes, irrespective of their characteristics, or current treatment protocol. Active involvement of patients, for example, by using a decision aid, might lead to improved therapy adherence.

Acknowledgments The authors thank Niels Hameleers MSc for his assistance in choosing the appropriate statistical analyses and Rowan Smeets Msc (both employed at Maastricht University) for her assistance in textually optimizing the methodology content.

\section{Compliance with ethical standards}

Conflicts of interest None.

\section{Appendix}

Table 5 Subgroup analysis age

\begin{tabular}{|c|c|c|c|}
\hline & $<65$ years & $>65$ years & $p$ value \\
\hline Efficacy & $\begin{array}{l}3.28 * \\
(95 \% \text { CI } 2.53 / 4.30)\end{array}$ & $\begin{array}{l}1.58^{*} \\
(95 \% \text { CI } 1.16 / 2.15)\end{array}$ & 0.00 \\
\hline $\begin{array}{l}\text { Side effects; } \\
\text { gastro-intestinal problems }{ }^{1}\end{array}$ & -1.35 & -1.31 & $\mathrm{~N} / \mathrm{a}$ \\
\hline $\begin{array}{l}\text { Side effects; } \\
\text { flu-like symptoms }\end{array}$ & $\begin{array}{l}0.91 * \\
(95 \% \text { CI } 0.44 / 1.39)\end{array}$ & $\begin{array}{l}0.78 * \\
(95 \% \text { CI } 0.49 / 1.07)\end{array}$ & 0.65 \\
\hline Side effects; on the skin & $\begin{array}{l}0.44 * \\
(95 \% \text { CI } 0.07 / 0.81)\end{array}$ & $\begin{array}{l}0.53 * \\
(95 \% \text { CI } 0.28 / 0.77)\end{array}$ & 0.14 \\
\hline Tablet weekly ${ }^{1}$ & 0.37 & 0.04 & N/a \\
\hline Tablet monthly & $\begin{array}{l}0.65 * \\
(95 \% \text { CI } 0.19 / 1.11)\end{array}$ & $\begin{array}{l}0.69 \\
(95 \% \text { CI } 0.46 / 0.92)\end{array}$ & 0.04 \\
\hline Subcutaneous 3 monthly & $\begin{array}{l}-0.18 \\
(95 \% \mathrm{CI}-0.63 / 0.27)\end{array}$ & $\begin{array}{l}-0.08 \\
(95 \% \mathrm{CI}-0.41 / 0.25)\end{array}$ & 0.68 \\
\hline Subcutaneous 6 monthly & $\begin{array}{l}0.58 \\
(95 \% \mathrm{CI}-0.18 / 1.34)\end{array}$ & $\begin{array}{l}0.50 * \\
(95 \% \text { CI } 0.03 / 0.97)\end{array}$ & 0.93 \\
\hline Intravenous 3 monthly & $\begin{array}{l}-1.92 * \\
(95 \% \text { CI }-3.24 /-0.59)\end{array}$ & $\begin{array}{l}-1.22 * \\
(95 \% \mathrm{CI}-1.65 / 0-.79)\end{array}$ & 0.17 \\
\hline Intravenous 12 monthly & $\begin{array}{l}0.49 \\
(95 \% \mathrm{CI}-0.22 / 1.21)\end{array}$ & $\begin{array}{l}0.07 \\
(95 \% \mathrm{CI}-0.30 / 0.45)\end{array}$ & 0.03 \\
\hline
\end{tabular}

*Significance level $<0.05$

${ }^{1}$ Reference value 
Table 6 Subgroup analysis gender

\begin{tabular}{|c|c|c|c|}
\hline & Female & Male & $p$ value \\
\hline Efficacy & $\begin{array}{l}3.53 * \\
(95 \% \text { CI } 2.25 / 2.99)\end{array}$ & $\begin{array}{l}1.86^{*} \\
(95 \% \text { CI } 1.06 / 3.28)\end{array}$ & 0.00 \\
\hline $\begin{array}{l}\text { Side effects; } \\
\text { gastro-intestinal problems }{ }^{1}\end{array}$ & -1.45 & -1.06 & $\mathrm{~N} / \mathrm{a}$ \\
\hline $\begin{array}{l}\text { Side effects; } \\
\text { flu-like symptoms }\end{array}$ & $\begin{array}{l}0.81 * \\
(95 \% \text { CI } 0.54 / 1.08)\end{array}$ & $\begin{array}{l}0.69 \\
(95 \% \mathrm{CI}-0.14 / 1.52)\end{array}$ & 0.96 \\
\hline Side effects; on the skin & $\begin{array}{l}0.64 \\
(95 \% \text { CI } 0.39 / 0.90)\end{array}$ & $\begin{array}{l}0.37 \\
(95 \% \mathrm{CI}-.56 / 1.30)\end{array}$ & 0.38 \\
\hline Tablet weekly ${ }^{1}$ & -0.73 & 0.13 & N/a \\
\hline Tablet monthly & $\begin{array}{l}0.57 * \\
(95 \% \text { CI } 0.26 / 0.87)\end{array}$ & $\begin{array}{l}1.10 * \\
(95 \% \text { CI } 0.24 / 1.96)\end{array}$ & 0.62 \\
\hline Subcutaneous 3 monthly & $\begin{array}{l}0.19 \\
(95 \% \mathrm{CI}-0.10 / 0.47)\end{array}$ & $\begin{array}{l}-0.52 \\
(95 \% \mathrm{CI}-1.33 / 0.29)\end{array}$ & 0.88 \\
\hline Subcutaneous 6 monthly & $\begin{array}{l}0.91 * \\
(95 \% \text { CI } 0.46 / 1.35)\end{array}$ & $\begin{array}{l}0.29 \\
(95 \% \mathrm{CI}-0.72 / 1.30)\end{array}$ & 0.91 \\
\hline Intravenous 3 monthly & $\begin{array}{l}-1.52^{*} \\
(95 \% \mathrm{CI}-1.97 /-1.06)\end{array}$ & $\begin{array}{l}-0.94 \\
(95 \% \mathrm{CI}-2.24 / 0.36)\end{array}$ & 0.30 \\
\hline Intravenous 12 monthly & $\begin{array}{l}0.59^{*} \\
(95 \% \text { CI } 0.14 / 1.04)\end{array}$ & $\begin{array}{l}-0.06 \\
(95 \% \mathrm{CI}-1.39 / 1.27)\end{array}$ & 0.39 \\
\hline
\end{tabular}

*Significance level $<0.05$

${ }^{1}$ Reference value

Table 7 Subgroup analysis prior fracture

\begin{tabular}{|c|c|c|c|}
\hline & No prior fracture & Prior fracture & $p$ value \\
\hline Efficacy & $1.86^{*}$ & $2.42 *$ & 0.00 \\
\hline $\begin{array}{l}\text { Side effects; } \\
\text { gastro-intestinal problems }{ }^{1}\end{array}$ & $\begin{array}{l}(95 \% \text { BI. 1.47/2.35) } \\
-1.00\end{array}$ & $\begin{array}{l}(95 \% \text { BI. } 1.75 / 3.35) \\
-1.62\end{array}$ & $\mathrm{~N} / \mathrm{a}$ \\
\hline Side effects; & $0.64 *$ & $1.15^{*}$ & 0.96 \\
\hline $\begin{array}{l}\text { flu-like symptoms } \\
\text { Side effects; on the skin }\end{array}$ & $\begin{array}{l}(95 \% \text { BI. } 0.35 / 0.61) \\
0.35^{*}\end{array}$ & $\begin{array}{l}\text { (95\% BI. 083/1.48) } \\
0.47 *\end{array}$ & 0.38 \\
\hline Tablet weekly ${ }^{1}$ & $\begin{array}{l}(95 \% \text { BI. } 0.10 / 0.61) \\
-2.00\end{array}$ & $\begin{array}{l}\text { (95\% BI. } 0.10 / 0.83 \text { ) } \\
-1.14\end{array}$ & N/a \\
\hline Tablet monthly & $\begin{array}{l}0.54 * \\
(95 \% \text { BI. } 0.32 / 0.76)\end{array}$ & $\begin{array}{l}0.69 * \\
(95 \% \text { BI. } 0.27 / 1.10)\end{array}$ & 0.62 \\
\hline Subcutaneous 3 monthly & $\begin{array}{l}-0.20 \\
(95 \% \text { BI. }-0.30 / 0.26)\end{array}$ & $\begin{array}{l}0.07 \\
(95 \% \text { BI. }-0.47 / 0.62)\end{array}$ & 0.88 \\
\hline Subcutaneous 6 monthly & $\begin{array}{l}0.47 * \\
(95 \% \text { BI. } 0.11 / 0.84)\end{array}$ & $\begin{array}{l}0.73 * \\
(95 \% \text { BI. }-1.73 /-0.61)\end{array}$ & 0.91 \\
\hline Intravenous 3 monthly & $\begin{array}{l}-1.07 * \\
(95 \% \text { BI. }-1.52 /-0.62)\end{array}$ & $\begin{array}{l}-1.17^{*} \\
(95 \% \text { BI. }-1.73 /-0.61)\end{array}$ & 0.32 \\
\hline Intravenous 12 monthly & $\begin{array}{l}0.36 \\
(95 \% \text { BI. }-0.04 / 0.75)\end{array}$ & $\begin{array}{l}-0.12 \\
(95 \% \text { BI. }-0.83 / 0.59)\end{array}$ & 0.39 \\
\hline
\end{tabular}

*Significance level $<0.05$

${ }^{1}$ Reference value 
Table 8 Subgroup analysis fear of needles

Table 9 Relative importance of attributes per subgroup

\begin{tabular}{|c|c|c|c|}
\hline & Fear of needles & No fear of needles & $p$ value \\
\hline Efficacy & $\begin{array}{l}4.85 \\
(95 \% \text { CI } 4.55 / 5.16)\end{array}$ & $\begin{array}{l}2.12 \\
(95 \% \text { CI } 1.78 / 2.54)\end{array}$ & 0.83 \\
\hline $\begin{array}{l}\text { Side effects; } \\
\text { gastro-intestinal problems }{ }^{1}\end{array}$ & -0.74 & 0.02 & N/a \\
\hline $\begin{array}{l}\text { Side effects; } \\
\text { flu-like symptoms }\end{array}$ & $\begin{array}{l}0.44 \\
(95 \% \mathrm{CI}-0.35 / 1.22)\end{array}$ & $\begin{array}{l}0.61 \\
(95 \% \text { CI } 0.43 / 0.79)\end{array}$ & 0.96 \\
\hline Side effects; on the skin & $\begin{array}{l}1.30 \\
(95 \% \text { CI } 0.68 / 1.91)\end{array}$ & $\begin{array}{l}0.37 \\
(95 \% \text { CI } 0.15 / 0.59)\end{array}$ & 0.28 \\
\hline Tablet weekly ${ }^{1}$ & 2.02 & 0.80 & N/a \\
\hline Tablet monthly & $\begin{array}{l}0.89 * \\
(95 \% \text { CI } 0.17 / 1.62)\end{array}$ & $\begin{array}{l}0.46 \\
(95 \% \text { CI } 0.27 / 0.65)\end{array}$ & $<0.01$ \\
\hline Subcutaneous 3 monthly & $\begin{array}{l}0.01 \\
(95 \% \text { CI }-0.77 / 0.79)\end{array}$ & $\begin{array}{l}-0.08 \\
(95 \% \mathrm{CI}-0.33 / 0.16)\end{array}$ & 0.75 \\
\hline Subcutaneous 6 monthly & $\begin{array}{l}0.49 \\
(95 \% \mathrm{CI}-0.57 / 1.55)\end{array}$ & $\begin{array}{l}0.39 \\
(95 \% \text { CI } 0.04 / 0.75)\end{array}$ & 0.91 \\
\hline Intravenous 3 monthly & $\begin{array}{l}-2.01 * \\
(95 \% \mathrm{CI}-2.96 /-1.33)\end{array}$ & $\begin{array}{l}-0.88 \\
(95 \% \mathrm{CI}-1.94 /-0.57)\end{array}$ & 0.05 \\
\hline Intravenous 12 monthly & $\begin{array}{l}-0.40 \\
(95 \% \mathrm{CI}-1.78 / 0.98)\end{array}$ & $\begin{array}{l}0.31 \\
(95 \% \mathrm{CI}-0.02 / 0.63)\end{array}$ & 0.16 \\
\hline
\end{tabular}

*Significance level $<0.05$

${ }^{1}$ Reference value

\begin{tabular}{llll}
\hline & Efficacy $(\%)$ & Side effects $(\%)$ & Mode of administration (\%) \\
\hline All patients & 39 & 30 & 31 \\
Females & 37 & 31 & 33 \\
Males & 33 & 31 & 36 \\
$>65$ years & 28 & 37 & 34 \\
$<65$ years & 41 & 28 & 32 \\
Fracture (yes) & 36 & 32 & 32 \\
Fracture (no) & 34 & 39 & 26 \\
Fear of needles (yes) & 44 & 19 & 37 \\
Fear of needles (no) & 68 & 24 & 8 \\
\hline
\end{tabular}




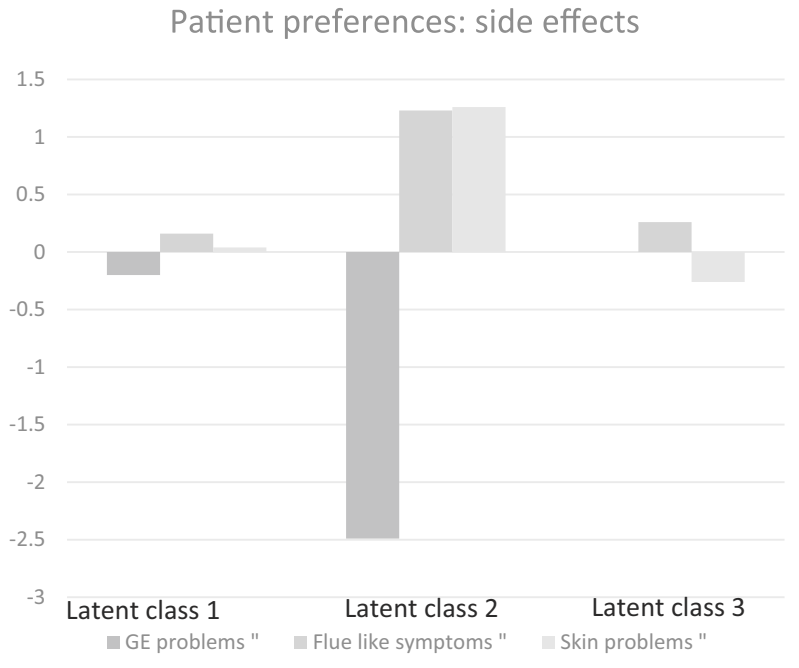

Fig. 2 Patients' preferences and side effects

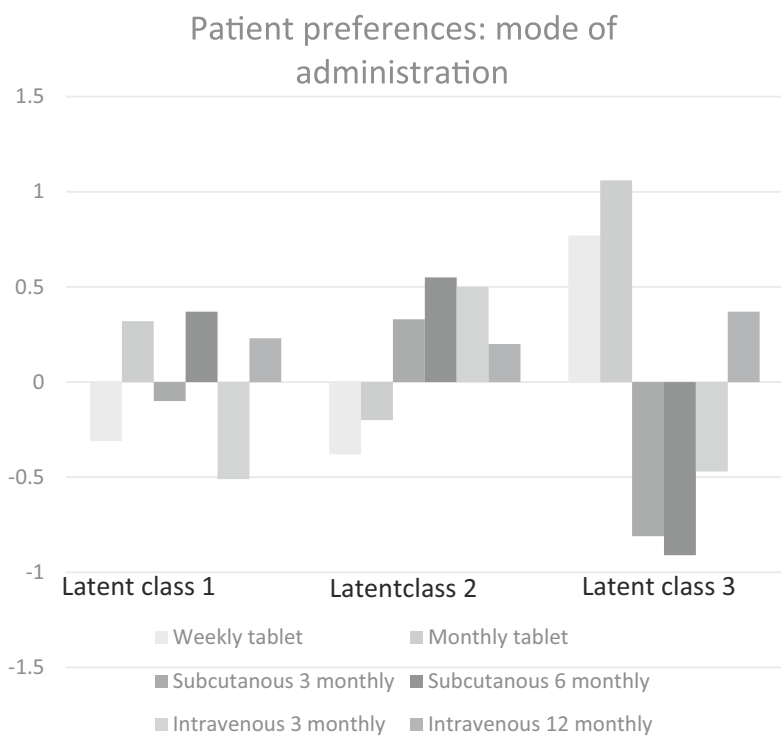

Fig. 3 Patients' preferences; mode of administration

Open Access This article is distributed under the terms of the Creative Commons Attribution-NonCommercial 4.0 International License (http:// creativecommons.org/licenses/by-nc/4.0/), which permits any noncommercial use, distribution, and reproduction in any medium, provided you give appropriate credit to the original author(s) and the source, provide a link to the Creative Commons license, and indicate if changes were made.

\section{References}

1. Ross S, Samuels E, Gairy K, Iqbal S, Badamgarav E, Siris E (2011) A meta-analysis of osteoporotic fracture risk with medication nonadherence. Value Health 14(4):571-581

2. Hiligsmann M, Rabenda V, Gathon HJ, Ethgen O, Reginster JY (2010) Potential clinical and economic impact of nonadherence with osteoporosis medications. Calcif Tissue Int 86(3):202-210
3. Ijzerman MJ, Steuten LMG (2011) Early assessment of medical technologies to inform product development and market access: a review of methods and applications. Appl Health Econ Health Policy 9:331-347

4. Mühlbacher AC, Johnson FR (2017) Giving patients a meaningful voice in European health technology assessments: the role of health preference research. Patient. 10:527-530

5. Hiligsmann M, Dellaert BG, Dirksen CD, Watson V, Bours S, Goemaere S et al (2017) Patients' preferences for antiosteoporosis drug treatment: a cross-European discrete choice experiment. Rheumatol (Oxford) 56(7):1167-1176

6. Silverman S, Calderon A, Kaw K, Childers TB, Stafford BA, Brynildsen W, Focil A, Koenig M, Gold DT (2013) Patient weighting of osteoporosis medication attributes across racial and ethnic groups: a study of osteoporosis medication preferences using conjoint analysis. Osteoporos Int 24(7):2067-2077

7. Laba T-L (2014) Using discrete choice experiment to elicit patient preferences for osteoporosis drug treatments: where to from here? Arthritis Res Ther 16(2):106

8. Zhou M, Thayer WM, Bridges JFP (2018) Using latent class analysis to model preference heterogeneity in health: a systematic review. Pharmacoeconomics. 36(2):175-187

9. Hiligsmann M, van Durme C, Geusens P, Dellaert BGC, Dirksen $C D$, van der Weijden $T$ et al (2013) Nominal group technique to select attributes for discrete choice experiments: an example for drug treatment choice in osteoporosis. Patient Prefer Adherence

10. Coast J, Al-Janabi H, Sutton EJ, Horrocks SA, Vosper AJ, Swancutt DR et al (2012) Using qualitative methods for attribute development for discrete choice experiments: issues and recommendations. Health Econ 21:730-741

11. Hiligsmann M, Dellaert BG, Dirksen CD, van der Weijden T, Goemaere S, Reginster J-Y, Watson V, Boonen A (2014) Patients' preferences for osteoporosis drug treatment: a discrete-choice experiment. Arthritis Res Ther 16(1):R36-R36 Available from: http:// www.ncbi.nlm.nih.gov/pmc/articles/PMC3979104/

12. Henser DA, Rose JM, Greene WH (2007) Applied choice analysis: a primer. J Am Stat Assoc 102(477):1-390

13. Louviere JJ, Hensher DA, Swait JD, et al. (2000). Stated choice methods, analysis and applications. Cambridge University Press (Vol. 53, pp. 1584-9). https://doi.org/10.1017/cbo9780511753831

14. Adamowicz W, Louviere J, Williams M (1994) Combining revealed and stated preference methods for valuing environmental amenities. J Environ Econ Manage 26(3):271-292

15. Bech M, Gyrd-Hansen D Effects coding in discrete choice experiments. Health Econ 14(10):1079-1083

16. Atkinson-Clark E, Charokopou M, Van Osselaer N, Hiligsmann M (2018) A discrete-choice experiment to elicit preferences of patients with epilepsy for self-management programs. Epilepsy Behav 79:58-67

17. Lanza ST, Rhoades BL (2013) Latent class analysis: an alternative perspective on subgroup analysis in prevention and treatment. Prevention science : the official journal of the Society for Prevention Research 14(2):157-168. https://doi.org/10.1007/s11121-011-0201-1

18. Muthén BO, Muthén LK (2000) Integrating person-centered and variable-centered analyses: growth mixture modeling with latent trajectory classes. Alcohol Clin Exp Res 24:882-891

19. de Bekker-Grob EW, Rose JM, Donkers B, Essink-Bot M-L, Bangma CH, Steyerberg EW (2013) Men's preferences for prostate cancer screening: a discrete choice experiment. Br J Cancer

20. Bozdogan H (2000) Akaike's information criterion and recent developments in information complexity. J Math Psychol 44(1):62-91

21. Weiss TW, McHorney CA (2007) Osteoporosis medication profile preference: results from the PREFER-US study. Health Expect 10(3):211-223

22. Carnevale V, Nieddu L, Romagnoli E, Bona E, Piemonte S, Scillitani A, Minisola S (2006) Osteoporosis intervention in ambulatory patients with previous hip fracture: a multicentric, nationwide Italian survey. Osteoporos Int 17(3):478-483 
23. Freemantle N, Satram-Hoang S, Tang ET, Kaur P, MacArios D, Siddhanti $S$ et al (2012) Final results of the DAPS (denosumab adherence preference satisfaction) study: a 24-month, randomized, crossover comparison with alendronate in postmenopausal women. Osteoporos Int 23(1):317-326

24. Tuinhout M, van Roermund PM (2015) Richtlijn Osteoporose en fractuurpreventie. PodoSophia 23:23-25

25. Gu T, Eisenberg Lawrence DF, Stephenson JJ, Yu J (2016) Physicians' perspectives on the treatment of osteoporosis patients with bisphosphonates. Clin Interv Aging 11:1-8

26. Fourie H, Floyd S, Marshall B (2015) Exploring New Zealand orthopaedic nurses' knowledge of osteoporosis. Orthop Nurs 34(1):29-35

27. Van Camp YP, Van Rompaey B, Elseviers MM (2013) Nurse-led interventions to enhance adherence to chronic medication: systematic review and meta-analysis of randomised controlled trials. Eur J Clin Pharmacol

28. Verloo H, Chiolero A, Kiszio B, Kampel T, Santschi V (2017) Nurse interventions to improve medication adherence among discharged older adults: a systematic review. Age Ageing 46:747754

29. Guix-Comellas EM, Rozas-Quesada L, Force-Sanmartín E, Estrada-Masllorens JM, Galimany-Masclans J, Noguera-Julian A (2015) Influence of nursing interventions on adherence to treatment with antituberculosis drugs in children and young people: research protocol. J Adv Nurs 71(9):2189-2199

30. Dhib-Jalbut S, Markowitz C, Patel P, Boateng F, Rametta M (2012) The combined effect of nursing support and adverse event mitigation on adherence to interferon beta-1b therapy in early multiple sclerosis. Int J MS Care 14:198-208
31. Parsons JT, Golub SA, Rosof E, Holder C (2007) Motivational interviewing and cognitive-behavioral intervention to improve HIV medication adherence among hazardous drinkers: a randomized controlled trial. J Acquir Immune Defic Syndr 46:443-450

32. Kendler DL, Macarios D, Lillestol MJ, Moffett A, Satram-Hoang S, Huang J et al (2014) Influence of patient perceptions and preferences for osteoporosis medication on adherence behavior in the Denosumab Adherence Preference Satisfaction study. Menopause (10723714) 21(1):25-32

33. Smallwood AJ, Schapira MM, Fedders M, Neuner JM (2017) A pilot randomized controlled trial of a decision aid with tailored fracture risk tool delivered via a patient portal. Osteoporos Int 28(2):567-576

34. Hiligsmann M, Ronda G, van der Weijden T, Boonen A (2016) The development of a personalized patient education tool for decision making for postmenopausal women with osteoporosis. Osteoporos Int 27(8):2489-2496

35. Sale JEM, Gignac MA, Hawker G, Frankel L, Beaton D, Bogoch E, Elliot-Gibson V (2011) Decision to take osteoporosis medication in patients who have had a fracture and are "high" risk for future fracture: a qualitative study. BMC Musculoskelet Disord 12

36. LeBlanc A, Wang AT, Wyatt K, Branda ME, Shah ND, Van Houten $\mathrm{H}$ et al (2015) Encounter decision aid vs. clinical decision support or usual care to support patient-centered treatment decisions in osteoporosis: the osteoporosis choice randomized trial II. PLoS One 10(5):e0128063. https://doi.org/10.1371/journal.pone.0128063

Publisher's note Springer Nature remains neutral with regard to jurisdictional claims in published maps and institutional affiliations. 